\title{
UNDERSTANDING STUDENT DRIVERS AND OBSTACLES TOWARD MIS MAJOR FROM THE PERSPECTIVE OF AN ARAB COUNTRY: THE CASE OF KUWAIT
}

\author{
Kamel Rouibah, College of Business Administration, Kuwait University, krouibah@cba.edu.kw
}

\begin{abstract}
Selecting a college major represents a strategic life decision making over a period of time, especially considering the commitment of time and resources. This is a riskiest decision which has a significant impact on the career and future prospects of undergraduate students. Unlike previous studies which focused on a quantitative approach in understanding what attracts college undergraduates to choose MIS major in western business schools, this study focuses on the subject, in a developing Arab country, using a qualitative approach. This study is the part of a large project that aims to develop a grounded theory model. In this study three research questions are investigated: What factors lead undergraduate students to enroll in MIS? What factors lead student to select other majors instead of MIS? What items/attributes are used to measure each driver/ inhibitor toward the MIS major. Data were collected using a qualitative approach based on open-ended questions with 195 students. Results revealed existence of thirteen drivers toward MIS major and eleven inhibitors, among them three were identified for the first time. These are: effect of group, perceived curiosity and perceived enjoyment. This study discusses these findings as well as their implication for management and research.
\end{abstract}

Keywords: Choice of major, MIS enrollments, enrollment factors, selecting MIS, obstacles to MIS, MIS careers

\section{INTRODUCTION}

Management Information Systems (MIS) is the study of people, organization and technology. Majority of information system programs are located in business schools, and may have different names such as management information systems, computer information systems, information sciences, business information systems, or information management. All MIS degrees combine business and computing topics and depending on the type of programs, emphasis is given either to management or to information systems.

Selecting a college major is a turning point in a student's life, the consequence of which has an extensive impact on students' future career, especially considering the commitment of time and resources. In short this is the riskiest decision taken by a student in his/her life as this decision can alter his future. Also it is a complex socio-behavioral phenomenon that has received an extensive research consideration over the last few years. Therefore, it is not surprising that Roese and Summerville [1] cite in meta-analytical evidence that the most frequently identified life regret for Americans involve in their educational choices.

\section{Research motivation}

The Bureau of Labor Statistics [2] has predicted a good future for the MIS/IT field in the future (2006-2016) in term of growth and high salaries. The report stated that:

Prospects for qualified computer and information systems managers should be excellent. Fast-paced occupational growth and the limited supply of technical workers will lead to a wealth of opportunities for qualified individuals. While technical workers remain relatively scarce in the United States, the demand for them continues to rise. This situation was exacerbated by the economic downturn in the early 2000s, when many technical professionals lost their jobs. Since then, many workers have chosen to avoid this work since it is perceived to have poor prospects. Workers with specialized technical knowledge and strong communications skills will have the best prospects. People with management 


\section{Issues in Information Systems}

Volume 13, Issue 2, pp. 58-71, 2012

skills and an understanding of business practices and principles will have excellent opportunities, as companies are increasingly looking to technology to drive their revenue.

Despite the positive expected growth of MIS and IT related jobs in the future, and even though the job market remains strong, declining enrollment in MIS departments in colleges of business has been a concern for many MIS programs and universities, and was well document in many studies $[3,4,5,6,7,8,9,10,11]$. This trend continues and seems to remain a real concern for many MIS departments and MIS professionals across different business schools $[12,13]$ which even has led some universities to completely dismantle their MIS programs. Enrollment concern has been a common observation in different countries such as USA, Australia, Canada, South Africa, and Western European countries [14]. The same trend was observed in Kuwait and this is evident from the following table, which depicts the number of students graduated from MIS majors and other majors, from the College of Business Administration at Kuwait University, where we can see a noticeable decrease of enrollment in MIS major.

Table 1. Graduated MIS students between 2004 and 2011

\begin{tabular}{|l|c|c|c|c|}
\hline \multirow{2}{*}{ Years } & \multicolumn{3}{|c|}{ Graduated In MIS } & Graduated in other \\
\cline { 2 - 4 } & Male & Femajors & Total & \\
\hline $2004 / 2005$ & 37 & 78 & 115 & 440 \\
\hline $2005 / 2006$ & 31 & 97 & 114 & 549 \\
\hline $2006 / 2007$ & 3 & 19 & 22 & 404 \\
\hline $2007 / 2008$ & 8 & 5 & 11 & 460 \\
\hline $2008 / 2009$ & 10 & 15 & 25 & 481 \\
\hline $2009 / 2010$ & 9 & 19 & 28 & 443 \\
\hline $2010 / 2011$ & 61 & 18 & 29 & 557 \\
\hline
\end{tabular}

This phenomenon has been the subject of discussions in several workshops and conferences. For example, the Australian Conference in Information System [15] made the subject a central discussion. It was argued that MIS disciplinary area within business and ICT "is still relatively immature when compared to others". Over the years we (as MIS) have had many scholarly debates about "what constitutes the IS discipline and what is the acceptable methodology to advance core knowledge and theory in the area". ACIS also added:

In spite of all of the excellent scholarly work conducted globally and locally within Australia in IS, practitioners and students still often argue exhaustively about the articulation and recognition of what the IS discipline is about. Our colleagues in other disciplines often fail to see where our scholarly contributions lie and our universities continually restructure our position within them. Could it be that the accommodating nature of the discipline and our interdisciplinary appeal may also be contributing to our difficulty in identifying, defining, and positioning what it is that we do.

Such lack of recognition both by business students and by other researchers in the MIS field, led to the weak enrollment in MIS major.

\section{Research objectives}

While previous studies focused on understanding what attract college undergraduates to choose MIS as their major, surprisingly no studies, except [16], focused on the issue in concerned colleges that belong to less developed countries, including Arab countries. In addition, most past studies on motives to enroll in MIS, limited their focus solely on quantitative approach. Thus a large number of these studies covered the issue from the researcher's perspective. However, very few studies adopted a qualitative approach which focuses on the students' perception of motives to enroll or not in MIS major [6]. While such studies contributed to highlight a number of factors that lead 


\section{Issues in Information Systems}

Volume 13, Issue 2, pp. 58-71, 2012

students to enroll in MIS major, the factors validity is questioned when the subjects belong to another culture where collectivism dimension is a prime determinant in peoples' decision. Arab culture is different from western culture and obviously students in different culture may have different motives and influences in their choices of MIS major.

This study sheds light on the issue from a different view point (an Arab perspective), than that of the western researches on the issue, and explores the areas where western researchers do not have enough knowledge about the Arab region. The current study, is the part of a large project that aims to, address this issue through four primary objectives: The first is to understand what attract college undergraduate students to choose MIS as their major. The second objective is to understand what factors deter students from selecting the MIS major. The third one is to conduct an empirical study in order to identify which factors among those identified in the current qualitative approach are more important when students select MIS major. The last objective is to identify factors and items that will be used to develop a theory-based model to reflect why business students in Arab culture decide to select MIS. Exploring the above objectives is mandatory in order to compare and synthesize findings across similar studies, as recommended by MIS researchers [28]. However, the current study will cover only the first two objectives, while the other two will be covered by subsequent studies.

In order to reverse the declining trend, responsible faculty members of MIS majors need to understand factors that drive students to choose their major. "Because enrollment remains a critical issue in MIS departments, it is important to understand factors by which students choose their major and, in particular, those students who choose similar, but not MIS, majors" [11]. In business administration colleges, MIS major suffers competition from alternative business majors. There are many similarities between MIS majors and other business majors "given that they are all housed in the College of Business. All business students take similar core and foundation business courses, including courses in accounting, economics, and introductory courses in management, marketing, and finance. Most business majors require students to take an introduction to MIS course, and perhaps a computer skills course, both of which are typically service courses offered by MIS Departments" [11]. Therefore, it would be helpful to attract students to a discipline before a labor shortage becomes obvious.

\section{LITERATURE REVIEW}

Factors that influence students to pick a particular major have been well-researched across a variety of majors including traditional business major (accounting, finance, marketing) and MIS. The following paragraphs review a subset of those studies.

\section{Past studies on general major selection}

Cohen and Hanno [17] studied the reasons why students enrolled in accounting major. They found that students not choosing accounting may believe that accounting is too number oriented and boring. Choice of major is also affected by the referents, whom they believe as a source for good advises. Simons et al. [19] reviewed 21 studies related to choice-of-major. They identified four important determinant categories in major selection. These are: earnings, career opportunities, career characteristics, and characteristics of the major. Also they found that the most important career factors when selecting a major were financial rewards, job availability, and interest in the major/career. In New Zealand Tan and Laswad [20] found that students' intentions to major in accounting and nonaccounting is affected by three factors (personal, referents, and control). Further analysis revealed that the students' major intentions are influenced by important referents' perception particularly their parent's perception. Beggs et al., [21] focused on factors by which undergraduate students select their academic majors in general. They used a mix of qualitative and quantitative approach.

The qualitative approach revealed six important factors: Information search, match with interests, job characteristics, financial considerations; psycho/social benefits, and major attributes. Results of the qualitative study showed six factors, ordered by their importance: Match with interests, course/major attributes, job characteristics, financial considerations, psycho/social benefits, and information search. 


\section{Issues in Information Systems}

Volume 13, Issue 2, pp. 58-71, 2012

\section{Past studies on MIS major selection}

Several studies focused on what attract/ deter students from selecting the MIS/IT major $[9,10,11,14,16,22$, 23,24]. Hogan and Li [9] investigated why business students choose their major, how they perceive the MIS program. They found that, when students choose their major, three factors are determinants. These are: career related issues (prospects of the major are promising and that the major has well-paid jobs), students' interests toward MIS, and social and referent factor. With regard to students' perceptions about MIS major, those who already selected their major perceived that 'graduate students have good and well-paid jobs, MIS sounded interesting and cool, and I always wanted to work in MIS field when I was young'. However, MIS, which seemed easy to study and to graduate with, that ranked as the least one for enrollment, reflect the deterrent attitude of students to choose MIS major.

Saunders and Lockridge [10] reported the results of a survey of MIS graduates perceptions about MIS degree at an American business school. Results suggest that graduates share the view that a perception gap exists and that more emphasis needs to be placed on employability. They tend to believe that their program needs to become more aligned with the needs of employers. Graduates believe that business leaders should be involved more closely in determining the direction and content of their program.

Downey et al., [11] examined factors that shape attitudes toward choice of major, student's intention to work in his or her major field as well as the similarities and differences between two groups of business majors: MIS majors and non-MIS majors in USA. They found three factors that commonly influence all majors are: interest in the field, job availability, and job security. They also found many differences between the MIS majors and non-MIS majors in areas like: aptitude, social and personal image, workload of major, and influence of family, friends, other students, and instructors. They also found that difficulty of the major is an obstacle toward not selecting the major.

Walstrom et al. [14] focused on why students do not major in MIS, and what is important to students when they pick a major. They found that most students selected traditional majors (accounting, finance, marketing and management), and very few students (less than two percent) selected MIS major. Factors that drive students while selecting a major were grouped into three categories: personal interest and ability (i.e. self-efficacy) was identified as the highest ranking factor. Second was unique career-related factors offered by a particular field. It includes probability of working in the field after graduation, starting and long-term salary prospects, prestige of the profession, occupational growth forecasts, job security, opportunities for ongoing professional development, and reputation of the degree program at the university. The third factor was "social/referent sources" and was rated as the least important which consists of high school guidance counselors, university career services programs, university advisement center and family members.

Cohen and Parsotam [16] focused on IT career interests by South African university students. They found very low intentions amongst students to pursue an IT career. Occupational self-efficacy, computing experience, computer anxiety, computer self-efficacy, and perceived career rewards were found to be important factors. Student perceptions of the core introductory IS course is also an important determinant of their intentions.

Tillberg \& Cohoon [22] focused on what attracts female students to the computer science major. They found several factors which include: early experiences with computers, the match between a student's self-assessed abilities and the abilities required by computer science, and the features of computing careers. Zhang [23] identified job availability, interest in the IT major, difficulty of the curriculum, and the opinions of influential persons to students. $\mathrm{Li}$ and Thomson [24] focused on what is important to business students when they choose MIS Major, where do they learn about their majors, and what do they think of the MIS program. When student choose their MIS major author found that salary, job security, personal interest and easiness of the subject matters were the most drivers. With regard to where do students learn about their majors, authors found that information from Internet/Web, information from friends and family members were ranked first, followed second by information from major-related courses, while career counselors /academic advisor was the least ranked one. With regard to what do students think of the MIS program, answers of participants revealed that MIS jobs are stable and fast growing, MIS major/jobs 


\section{Issues in Information Systems}

Volume 13, Issue 2, pp. 58-71, 2012

sounded interesting and cool. Results also revealed that "MIS seems easy to study and to graduate with" was the least ranked one, indicating the complexity perception of studying MIS.

Ferrat et al., [29] conducted a qualitative study with 50 students in order to understand what is meant by "subject matter interest" when selecting their MIS major which they labeled as "smiFactors". Authors identified three broad factors that lead to select MIS: Job/Career prospects (including variety of jobs/career paths, job availability, employment security, advancement opportunities and salary) and self-efficacy beliefs. These two categories are common to the previous studies. Authors also identified a third and new category that includes three new subconstructs: technical focus, linking business and, and practical application of course work. The two first factors are unique to MIS, whereas the third one, practical application of course work applies to MIS as well as other majors and careers. The last sub construct, practical application of course work, includes attributes such as challenge/problem solving, creativity, social interaction, helping others, importance/utility to business, image/reputation, and change.

From the review of the above listed studies we can point out the following observations: only on occasion will a study directly compare MIS majors with the other business majors [14]. Also much of the research on this issue focuses on what attracts students to the MIS major, and less has been done on what deter undergraduate students from selecting MIS major using qualitative approach. Also it is notably visible that compared to studies conducted in the western universities, the problem receive due attention neither in less developed countries nor in the Arab countries, expect one study [16]. Finally, the preceding literature review identified many influencing factors. These are: characteristics major (workload of major, difficulty/ easiness of the curriculum), job characteristics (job security, perceived career rewards), job availability (employability), financial considerations (salary, starting salary), personal interest, self-efficacy and aptitude, social and personal image (influence of family, friends, other students, influence of instructors, and information search. Surprisingly, based upon the literature, we observed lack of comments relative to the ease of getting a particular degree or the ability to assess the relative advantage of some traditional major (accounting, finance, management, and marketing) compared to MIS, willingness to maintain high GPA with some instructors as well as characteristics related to instructors. Finally, except of Ferrat et al.,'s study [29] there are not enough studies / knowledge about what items can be used to assess different factors that lead to select MIS major or not, from the students' perspective.

\section{RESEARCH METHODOLOGY}

This study used a qualitative approach to investigate the drivers and obstacles of those intending to enroll in the MIS major using a sample of students in a business college in Kuwait. It consisted of a survey with an open-ended section in which respondents were asked to list as much as they can in a generic fashion, (i) what factors lead participant to select the MIS major if she/he plans to enroll in such a major? (ii) Why MIS is not attractive to student if she/he plans to enroll in another major different than MIS? Participants were invited to give their responses in both languages (Arabic and English). This was a voluntary assignment during the end of two courses: an introduction course to MIS and an introduction to e-commerce. Questionnaires were distributed to 250 students in seven classes between 2007 and 2010. However, 195 accepted to participate and returned completed questionnaires distributed as follow: 5.46\% (spring 2007), 31.8\% (fall 2008), 11.28 (spring 2008), 13.85\% (summer 2008), 24.1\% (Spring 2009), 10.26\% (summer 2009), and 3.08\% (Spring 2010).

Qualitative data was analyzed using an interpretive research methodology according to intentional analysis. According to Klein \& Myers [25] interpretive research can help IS researchers to better understand human thought and action in social and organizational contexts. It can help to produce useful insights into information systems phenomena. This methodology, "interpretive research" has been used in areas of information systems research such as: systems design, organizational intervention and management of IS and social implications of IS [26]. 


\section{Issues in Information Systems}

Volume 13, Issue 2, pp. 58-71, 2012

\section{RESULTS}

\section{Drivers toward selecting MIS major}

The qualitative approach showed twelve motives as the drivers for selecting MIS major by participants. Although the analysis of the qualitative data revealed some factors which are similar to previously identified categories, it also identifies new motives and gives more details about those identified driving factors. In the following sections we will briefly describe these factors as well as students' quotation.

1-Characteristics of major/ curriculum: As expected by the preceding literature review about MIS [9, 11, 23, 24] and non MIS major selection $[17,19,21]$ significant references to characteristics of the major/curriculum was observed. In this study also the respondents emphasize more on this factor, but with much more details than those highlighted by past studies. Participants mentioned that they are willing to enroll in the MIS because of several attributes. They stated the practical application of course work "IT intersects with our daily lives and it has a big contribution in organizations and in our lives, not to mention its importance in the field of economics". Participants also added easiness of the major "This major is easy". Others emphasized the link between the business and the technology "MIS explains to me the relationship between business and technology"; "MIS is useful because in the future every business process will be supported by IT", "MIS is useful because it helps to discuss global management and the relationship with computer system", "It helps to understand organization systems", "For me MIS is an interesting field, and it has a great influence in the business world ", "MIS gets involved in all business majors and probably these majors wouldn't function without it", "I am very interested in technology and using it in our life make it better, easier and more efficient". Rapid change of the curriculum is another attribute that attracted other students who quoted "MIS is, without a doubt, the most important and up-to date major I have ever studied". Creativity was also quoted by other participants "MIS is an interesting field which shows a lot of creativity in order to create new systems, and creativity is hard to find", "MIS allows me to do something creative ". Other students stated MIS complementarily with other majors "I consider MIS as a supportive tool for all the market aspects including finance". Other participant mentioned attractiveness of the major "I honestly find the major pretty much attractive everywhere in the world, not just in the American States, Europe and Japan, also in most of the Arab regions", "I find that the content of MIS major is interesting and attractive for me". Technology focus was also emphasized "The most interesting factors for me in MIS is networking, security, graphics and programming, I already know a lot about these subjects, and in the mean time I intend to learn more through MIS major". Finally, challenge of problem solving was another attractive attribute "MIS is the type of course that I like to study where you need to think and solve problems".

2-Characteristices related to Instructor: While past MIS [11] and non MIS [21] studies recognized that instructors are an important referent to drive selection of the MIS major, there was a lacking information about the instructors' attributes that attract students to go on with the reference. Our qualitative data analysis revealed six quoted attributes: active, cool, instructor's reputation, large knowledge, entertaining teaching style, and use of innovative teaching style. Active instructors: "MIS is a very attractive subject and entertaining especially if the instructor is very active". Cool instructors: "I like instructors of the department so far they are the coolest in the college departments". Good reputation: "Instructors who teach MIS have a very good reputation". Instructors with deeper knowledge: "Most important factor that attracts me to MIS major is that unlike other instructors in other major, most instructors in MIS major have deeper knowledge/ information. This is a wonderful thing". Instructors use entertaining teaching style "The impact of the instructors on students and making the courses attractive is an important factor that drives me to select the major". Instructors use innovative teaching style "I intend to major in MIS because the way we are learning this subject is fun, new, and unique and encourages me to learn more while I am happy and not bored".

3-Social impact: Consistent with previously identified factors in MIS [9, 11, 23; 14, 2414] and non MIS studies [17, 21] this study found referent as an important drive for participants to select their MIS major. These are pressure from family members (parents, grandfather, brother, cousin), influences of instructors, as well as friends and schoolmates. With regard to pressure from family members, some participants quoted "I selected the major because 


\section{Issues in Information Systems}

Volume 13, Issue 2, pp. 58-71, 2012

of the influence I got from my grandfather who was the manager of a big company", "My brother advised me to enroll in this major", "I have spoken to my cousins who majored in MIS, and they are very happy with their choice. I have also been speaking to my father who made the things very clear for me", "The impact of parents in students' decision making in major selection is due facto because parents are the primary source of advice for students", "I selected my major because of the advices I got from my bubbles and family" and "Most of my relatives have studied that major and they have advised me to enroll in it". Instructors also have influence on students "I selected MIS as my major because of the motivation I got from of my instructors", "I was persuaded from my instructor that I can achieve my goal by joining this major", "I know you won't believe me but within three classes, my instructor's influence created a lot of change in me and encouraged me to select MIS". Since Kuwait belongs to a collectivism culture, friends and trusted schoolmates also have strong influence on other students, "some of my friends said it's one of the most recommended jobs in Kuwait", "I chose MIS because of recommendations I got from my closest friends I trust", "My decision was based on my friends' recommendations", "I followed my colleagues and friend when selecting the major".

4- Self efficacy attributes: Consistent with previous MIS [14, 23; 16] and non MIS studies [20] students select a major when they are internally motivated and believe that they have self-efficacy and aptitude to succeed in this major. Our result confirm this factor and highlighted four attributes: capabilities to succeed in the major, matching of personal skills with those required by the major, availability of technical skills, technology, and willingness to achieve goals. Participants quoted "I feel, I can excel in this field, and my ambition is to become an expert in a big corporation", "The main factor that drove my choice to MIS was because my strengths in the classes are where speaking and creativity skills are needed and my weaknesses are in classes that require a lot of numbers and complications", "MIS is one of the major where I find myself good at", "I have chosen MIS major because it is compatible with my interests and focuses on computers, software and hardware", "I feel myself more capable of learning new courses in this major more than others", "I do have enough knowledge to deal with computers" and "I can achieve my goal through this major".

5-Match with interests attributes: Also consistent with the previously identified factors in MIS major studies [14, 23; 23, 24] and non MIS [19, 21] most of the study's participants emphasized the importance of the positive characteristics of major, the job market needs and prospects that will follow upon graduation, and synchronization with their own interests. This category appears to focus primarily on efficacy and challenges. Our results reveal five attributes which are: matches with personality, passion for the major, interest in technology, suitability with desires, and compatibility with interest. Here are examples of participants' quotations "MIS matches with my personality and interest", "I think in order for a person to be successful in his major the passion for the major must exist", "I like MIS the most because of my interest in technology", "The most important factor that drives me to select MIS is that it uses computers and I like working with computers", "This major is suitable with my desires", "I am so interested in technology and computers so MIS offers me what I want", "This major is compatible with my interest", "I intent to select the major that comply with my capabilities and abilities", "My intention to choose MIS as a major existed since I was in school", "I have always been interested in business organizations and technology, and MIS offers me this opportunity".

6-Job Characteristics: Consistent with the previously identified job characteristics in both in MIS [14; 29] and non MIS studies [21] many of the respondents emphasized this factor as an important consideration in selecting their academic majors. In our study we identified six attributes which are richer than previously indentified [29]. These attributes include match with job description, job with social interaction, job with technical skills, working conditions, career opportunities and job reputation. Match with job description was quoted by one participant "I have chosen the major as its characteristics match with the requirements of job descriptions in the market". For social interaction at workplace participants quoted "I found MIS very interesting and amusing specially because it will enable me to contact with people during work ", "Work in this major depends on communication with other employees to design new systems or to select systems package when buying new software". For job with technical skills others quoted "MIS is the backbone of organizational business processes and most jobs require support from IT", "One factor that drives my choice to MIS is that I prefer to work with computers and systems", MIS is a must in all organizations which cannot work without it". Working conditions were also emphasized "I feel jobs for MIS are 


\section{Issues in Information Systems}

Volume 13, Issue 2, pp. 58-71, 2012

much fun than marketing and other jobs", "MIS major offers the type of environment I like to work in". Career opportunities were also stressed "I will choose MIS major as a double major because it is very important in my career", "I like using technology that allows me to design advertisements that attract others", "MIS helps me to get my dream job", "It is a good major, and as far as I know it has a good future career", "Business market needs MIS graduated students who have the desire to work and to be creative", "MIS major is of great importance to me in term of future job". Finally job reputation was also cited "MIS major is considered as one of the finest jobs in Western countries and has a high esteem".

7- Perceived job availability: Besides job attributes, and consistent with previous identified factors in MIS [9, 10, $14,16,22 ; 23 ; 24 ; 29]$ and non MIS studies [19, 21], perceived job availability was identified as another important factors that drives students to enroll in MIS major. Three attributes were identified which include availability of variety of jobs, employment security and advancement opportunities. The first two drives are consistent with those of Ferrat et al. [29]. For advancement opportunities participants quoted "I see a good future in MIS because when a Kuwaiti student graduates in MIS he will have good opportunities to be hired in the private sector since the government forces companies to hire citizens (i.e. each company needs to hire a certain percentage of Kuwaitis in order to be eligible as tenders). That will give him an advantage because nowadays most MIS/ IT employees are non-Kuwaitis". For availability of variety of jobs other participant quoted "I feel that this major provides many opportunities for job careers", "I think the major is needed in all organizations", , "MIS is among the most wanted majors in Kuwait, I know it is ridiculous to base one's choice around what the market want the most, and not around what suits the person", "There is an increase demand on MIS graduates in the market", "Market opportunities are high for graduate MIS students". Finally as for employment security, other stated "I thought it is more desired after graduating when I am looking for a job", "MIS job opportunities after graduation are high in the market", and "I can easily find a job because it is almost a new major and highly demanded".

8- Financial considerations/ perceived value: Considering MIS [9, 10, 14, 16, 24; 29] and non MIS past studies $[19,21]$, and despite the fact that financial considerations are usually considered as a specific job attribute, this factor was mentioned so frequently by sample's participants, and hence we felt that it was important at this point to maintain job characteristic as a separate factor in the study. Two attributes were frequently mentioned: amount of salary, and additional benefits. Here are some participants' quotations: "I based my choice of major on the financial consideration like what salary would I get and what kind of benefits I will receive", "By choosing this major I would get excellent financial benefits".

9-Information Search: Past studies identified that students relied on personal sources of information in making decisions to enroll in MIS such as contacting family members, and their friends [21, 24]. But unlike these past studies, participants in this study mentioned other sources such as readings books, attending trainings on MIS courses, direct or indirect recommendations of people they knew. To our surprise neither personal information source nor impersonal information source (such as internet) were mentioned. Here are some their quotations: "I have read few books about that major, which made the major more attractive to me. Also, I have attended some interesting training lectures on the major which I liked more"; "After searching and reading more about MIS I changed my whole point of view about MIS"; "Personally I am really interested in MIS but the lack of enough information caused me not to know about MIS as a major, until my third course at the college".

10- Attitude: Finally consistent with past study on MIS [24; 29] and non MIS [21] the most cited factor is related to attitude of participants. Most of them frequently quoted: "I love Computers", "I like this major", "I am interested in MIS major and I have great joy to study it", "I will choose MIS as a double major because it is very important in my life in general and more specifically in my career ", "I do plan to select MIS as a second major, because nowadays it is impossible to succeed without the knowledge and usage of information systems", "I see that MIS is a very important major"; "MIS seems very interesting and how much it helps a business and makes things much easier".

In addition to the ten factors previously described, this study identified three new and additional factors in our qualitative inquiry not previously emphasized in the extant literature. 


\section{Issues in Information Systems}

Volume 13, Issue 2, pp. 58-71, 2012

11- Perceived enjoyment: The qualitative results suggest that some participants were influenced by an individual trait "perceived enjoyment" which received an extensive focus on information system adoption studies, but was ignored in past studies that focused on MIS enrollment. Expository exemplars include: "Studying MIS is very fun and interesting", "I am interested in computers and find that as enjoyable", "I intend to major in MIS because the way we are learning the subject is fun, new, and unique and encourages me to learn more and it is not boring", "I will select MIS major as it is fun to study".

12-Curiosity: Unlike past studies, this study also highlighted for the first time a new driver, curiosity, that has never been mentioned earlier. "I am curious to know the jobs that the MIS major provides" and "I am curious to know the MIS major".

13- Effect of group: Interestingly, this factor which has not been previously emphasized in any past study is identified here. The effect of a group occurs when a decision to adopt a certain behavior is affected by considering if the majority of the people around them adopt it or not. In one word we can say that an individual decision is linked to the group behavior. This factor is grounded in the network externality theory [27]. Specifically, the qualitative results suggest that some participants were influenced by their perceptions of how many students hold positive perceptions about the major "everybody says that MIS is required by firms and that gives me better chance for getting a job", "People around me told me that MIS major is nearly the same as computer science. Then I decided to enroll in the MIS major", "Apparently the interest of all firms in this major, from what I see and hear, is highly needed".

\section{Perceived obstacles to selecting a MIS major]}

This qualitative study not only focused on drivers toward MIS but also investigated the obstacle toward selection of the major. Results identified eleven inhibitors that prevented participants from enrollment in MIS. Most of those factors were never mentioned in any past qualitative study.

1- Difficulties of the major/curriculum: Five attributes related to the characteristics of the major make MIS far from student's interest. These attributes are: too technical oriented, bad prerequisite courses, rapid changes and hard to follow, too complex, and lack of attractiveness. For technical orientation/focus many participants stated "Most MIS courses are computer-based", "I have no interest in computers and programs", "I don't like to spend long time working with computer", "I am not interested in computer hardware, software or how they are used to make our jobs easy and efficient", "I don't select MIS because I am not computer driven and things related to it", "I don't like this major because a huge part is dedicated to programming with Visual Basic. I have tried programming once and I didn't really see myself in this field". It is a rapidly changing field and hard to catch up "MIS is updating rapidly and is connecting many other majors, which makes it hard to track and update". Participants did also experience bad prerequisite courses "I don't intend to major in MIS because of the impression I have got from my first course "introduction to computers", which was very bad". The major is too complex: "I find MIS weird major", and not attractive: "I think MIS is somehow boring, because I am interested neither in management nor in information systems", "Because the study of MIS depends on computers so it must be more practical rather than studying it from books as it is now". Others find MIS as difficulty and complex "I feel MIS is very difficult/ complex". With regard to these previously identified attributes only the "difficulty of the major" was identified by some quantitative studies $[11,23,24]$.

2- Instructor's bad reputation and teaching style. This study identified three characteristics related to instructors' teaching and reputation as inhibitors toward selecting MIS major: severity of instructors, relative advantage of other instructors in other majors, and bad experience in teaching prerequisite courses. According to the participants view, MIS instructors seem to be very severe with students and not giving them enough grades: "MIS department has a bad reputation it is not considering students in term of grades". Others stated the relative advantage of other instructors in other majors. In fact, this is most frequently quoted inhibitor. This is related to the desire of students to maintain their GPA as good as they wish compare to other major. "Most of instructors of the MIS department are not as good as other departments such as finance ". Others have experienced bad teaching experience in prerequisite 


\section{Issues in Information Systems}

Volume 13, Issue 2, pp. 58-71, 2012

courses "I didn't like the first class of Introduction To Computers", "I do not intend to major in MIS because I found in the introductory courses that it includes lot of material and information related to IT and it is difficult to study", "I find some difficulties to understand the course well".

3-Lack of self efficacy: Results of this qualitative study also identified lack of self efficacy as an important obstacle towards choosing MIS major and six reasons (attributes) were cited. Poor memorization, lack of computer skills, lack clarity of MIS objectives, relative advantage of other major compare to MIS, lack of motivation to study MIS, and student's weaknesses in English language. Poor memorization was also an obstacle "I am not very good at memorizing terms. I do not use computer very often and use it only for research homework and talking to friends", "I don't intent to major in MIS because it is complex, has a lot to study, and I am not good in remembering". Lack of computer skills was also emphasized "I am good only at the basic usage of computers", "I think I am not really good with computers. I use it for searching and for my free time that's all and when I took the course "introduction to computers" I learned about computer but I still don't know what byte and terabyte mean". Other participants stressed lack clarity of MIS objectives "I don't intend to major in MIS because of the weak understanding of its primary objectives". Another group of participant did intent to select other major because of its relative advantage over MIS "I can deal with management easier than with MIS", "Because of the difficulties that I see in MIS major and the low grades I got I find myself better in economics", "I am a person that loves to lead, manage, and make decisions, and finance major requires all these characteristics rather than MIS", "It was my dream to enroll in accounting since I was in high school ", "There are two main reasons that drive me to chose finance major. When I studied it I feel happy and excited to solve any issue in this major", "I like dealing with numbers, stock markets, invest my money and make profit, and not with MIS. Finance doesn't make me feel bored. I feel interested and happy during the lecture of finance", "MIS does not depend on math and mathematical equations where I am good at". Other stated lack of motivation to study MIS "I do not find self-motivation and strong desire to enroll and learn this major". Finally other stressed their weak English language "I think it is difficult to study and I am weak in English".

4- Mismatch with students' interests: Many participants quoted that MIS is not what they are looking for since it does not match with their interest. Expository exemplars include: "I am not sure if MIS is what I am looking for"; "I like numbers and algorithms since I was a kid and not interested in MIS", "I didn't select MIS because my interests have always been marketing since high school, and I have gone to business school to achieve that"; "I like technology and prefer to use it more than studying it"; "I found that this major don't match with my interests"; "MIS is not in my interests or field of attraction"; I am not interested in MIS"; "I didn't select MIS because I don't like studying MIS courses and I'm not interested in that science"; and "MIS major doesn't meet my ambitions". While others stated that they have no tendency / curiosity to know about the major "I am not so excited to study this major and go on with it".

5- Negative perception of job characteristics: Unlike participants who hold positive perceptions about MIS major, others were reluctant to enroll in this major for three negative motives: lack of social interaction in MIS related jobs, lack of career path, and lack of job reputation. They advocate lack of social interaction in jobs: "I like to work and interact with people more than with computer and computer devices". Lack of career path was also advanced by other participant as an obstacle "MIS isn't part of my academic achievements in the near future and I would consider taking it after, because graduate students don't have much careers"; and lack of job reputation: "MIS is a great major and one of the most wanted majors in the USA and Europe but not here in Kuwait, and this is what I think about MIS".

6-Lack of perceived job availability: Unlike positive perceptions of some participants, some negative perceptions about MIS majors is revealed in this study and following are the two negative motives that keep respondents away from MIS major: lack of employment security and lack of job availability. These are examples of participants' quotations: "In Kuwait I think MIS major is not practiced in a way that it should be practiced", "MIS major is not attracting me because Kuwait does not need a lot of specialized people in MIS, and most employees are hired from abroad", "you cannot work everywhere because the MIS major is not known by all companies as opposed to accounting", "while there are certainly many job opportunities in IT, it is getting ever more competitive with foreigners", "because MIS major is not well known in the private, and the government sector does not hire fresh 


\section{Issues in Information Systems}

Volume 13, Issue 2, pp. 58-71, 2012

graduate MIS in a department that relates to MIS jobs", "competition of qualified Indian expatriate labor force in Kuwait is a factors that drive me not to select MIS major", "I have no idea about workplaces where graduate MIS student will work", "only few companies in Kuwait give a complete recognition of the importance of information systems. Therefore, MIS would not be a good place to bright and be creative ", "people who graduate from MIS are not having good chances to work". Besides lacking employee security, others stressed lack of job availability. These are examples of participant' quotations: "MIS has no career in Kuwait", "the lack of MIS job opportunities and departments in companies", "the need of Kuwaiti MIS graduates in local business is low", "unlike accounting some firms don't use MIS", "some firms don't use MIS but all firms do use the Accounting", "I don't think MIS employment opportunities are good as other majors such accounting and finance. MIS departments in Kuwaiti companies need however some more time to develop".

7-Less financial considerations compare to other jobs: Unlike positive perceptions of students who show high tendency to enroll in MIS because of expected high salaries, others believe that the financial considerations of other majors are higher than those of MIS: "being an accountant means having a "financial status" which allow graduate accounting students to get more salaries than students in other majors".

8- Negative influence of social pressure: While past literature review and results of this study have shown that several social groups are the cause toward enrollment in MIS major, the same identified social groups (family members and friends) were also perceived to be inhibitors. For the influence of family members some participants stated "I enquired my family and friends about the valuable existing jobs and they mentioned accounting"; "I was thinking of MIS but then my cousin who took MIS as a major, shared his bad experience and hence I changed my attitude toward the major"; "My family owns a couple of companies and I am part of the next generation that will have to keep these companies going and even make them flourish, therefore I see that I need to be good in the area of management". With regard to influence exerted by friends and colleagues other participants quoted "Many of my friends did not advise me to select MIS major", "People told me that MIS is not very desirable"; "I chose finance because a friend told me that the CEO of the NBK (a very famous bank in Kuwait) and the CEO of Global Investment House (a famous investment company in Kuwait) majored in finance".

9- Anxiety from IT: Consistent with previous literature review [16], fear of using IT is cited by many participants as an important obstacle to enroll in MIS. Expository exemplars include: "I think the disadvantages are when the systems crash"; "If the computer damages I will be in trouble"; "I don't really think about MIS because it needs spending a lot of time on computers and I am not really a "computer lover". In addition to the routine work and having to deal with machines all the time"; "I have always faced some problems in understanding the whole computer systems"; "I feel anxious about using information technology"; "Many of the courses offered by MIS major are based on memorizing and this scares me"; "I truly prefer using my mind and doing manual work instead of being dominated by technology"; "I am really bad in computers and I don't like technology at all"; "I am not good in dealing with computers"; "I never liked any of my computer classes in school. I even did not like my first computer class at the university, even if it was light".

10-Negative effect of the group perceptions: Similar to the effect of external network observed for positive perceptions, other participants did mention this effect by quoting "I did not select MIS because rumors circulate that MIS has not good future career in Kuwait"; "I didn't choose MIS because nobody encouraged me to enroll in this major when I joined the College "; "Many students said that MIS is very difficult"; "I don't select MIS because it is rare to see a student major in MIS, most student would choose Accounting or Finance and maybe marketing for a change"; "I don't see lot of students chose MIS as their major". Other participants stressed the relative number of students who already selected other majors instead of MIS "I know a lot of people that are majoring in either accounting or finance, that's why MIS is my second choice, or if possible a doubled major"; "As many of my fellow colleagues have said, I will choose accounting".

11- Negative attitude towards the MIS major: Finally other participants stated that simply they don't like MIS: "I don't like computer and I don't see myself in MIS"; "MIS major needs continuous knowledge for graduate students 


\section{Issues in Information Systems}

Volume 13, Issue 2, pp. 58-71, 2012

which I hate"; "Although MIS is not nice and interesting major but I didn't select it because it's too difficult and hard when you study it"; and "I neither like to choose MIS nor to studying it".

\section{CONCLUSIONS}

A decrease in the enrollment in MIS major is a trend that has been observed in business colleges all over the world including Kuwait. Many factors have been investigated to explore the reasons behind this phenomenon by using, mostly, quantitative research approaches. Unlike past studies, this study adopted a qualitative approach and highlighted the reasons why a sample of Kuwaiti students intent to select or to reject MIS as their major. The study's sample size is large enough and included 195 students enrolled in a leading business administration school in Kuwait, which is an Arab country.

This study achieved two main contributions. First it succeeded to highlight thirteen drivers toward selection of the MIS major and eleven inhibitors that has attract less attention from western researchers. The driving factors are: characteristics of major/ curriculum, positive perceptions about instructors, social impact, self efficacy attributes, match with interest attributes, job characteristics, perceived job availability, financial consideration, information search, attitude, enjoyment, and curiosity. The last three factors are identified for the first time. Among the list of identified driver factors, only eleven were perceived to inhibit participants to select the MIS major in Kuwait. These are: difficulties of the major/curriculum, negative perceptions of job characteristics, lack of perceived job availability, less financial considerations compare to other jobs, negative influence of social network, negative effect of the group, anxiety from IT, and negative attitude towards the MIS major. Second, this study also succeeded to identify items to measure the thirteen factors, which could be used in the future to conduct a confirmatory analysis as well as to develop a theory based model.

This study suffers from two limitations. First, while it identifies a list of drivers/ inhibitor toward MIS selection, it does not provide any weighting/assessment of any identified factor using a quantitative approach. Second, results of this study cannot be compared to previous ones, and the influence of local culture, in the decision making process of the participants to select or reject MIS major, was not clearly identified in this study.

This study presents both management and research perspectives. From a management perspective this study provides to the managers responsible of business administration schools in Kuwait, a management tool (list of identified drivers/ obstacles), on how to act in order to increase students perceptions about the MIS and how to turn their negative perceptions into positive perceptions. It is hoped that this study gives the means to the responsible persons to focus on how to reduce the declining enrollment in MIS major, and create an awareness by removing the misconceptions about MIS majors in order to attract more business students to this major.

From a research perspective, this study, as it was stated in the introduction that this is the part of a larger project, and there are two subsequent activities that need to be carried out. The first activity consists to undertake a quantitative approach in order to assess the weighting of different factors in order to compare its results with previous studies as well as to show the unique factors related to the Arab culture. A second research perspective consists to carry out a future study that aims to develop a grounded theory model based on the thirteen attributes identified in this study, so that the expected model reflect the local culture, and students' view, and not the researcher's views.

\section{ACKNOWLEDGEMENTS}

This research was funded by Kuwait University, Research Grant IQ 03/10. The author acknowledges the Research Administration Project for its support. 


\section{Issues in Information Systems}

Volume 13, Issue 2, pp. 58-71, 2012

\section{REFERENCES}

1. Roese, N. J., \& Summerville, A. (2005). What we regret most and why. Personality and Social Psychology Bulletin, 31(9), 1273-85.

2. Bureau of labor statistics, (2010). Occupational Outlook Handbook, 2010-11 [online]. Available http://www.bls.gov/oco/oco2001.htm\#projections data

3. Foster, A.L. (2005). Student interest in computer science plummets: Technology companies struggle to fill vacant positions. The Chronicle of Higher Education, 51(38), [Online]. Available http://chronicle.com/article/Student-Interest-in-Computer/10912

4. Locher, M. (2007). IT Education: Where have all the young geeks gone. CIO, 20(15), 49-53.

5. Vegso, J. (2005). Interest in CS as a major drops among incoming freshmen. Computing Research News, 17(3) [online]. Available www.cra.org/CRN/articles/ may05/vegso

6. Ferratt, T.W., Hall, S.R., Prasad J. \& Wynn, D.W.Jr (2009). Why students choose MIS: what makes a majorjob-career in management information systems interesting? Proceedings of the special interest group on management information system's 47th annual conference on Computer personnel research [online], ACM New York, NY. Available: http://dl.acm.org/citation.cfm?id=1542140

7. Heinze, N., \& Hu, Q. (2009). Why college undergraduates choose IT: a multi-theoretical perspective. European Journal of Information Systems 18, 462-475

8. Downey, J., McGaughey, R., \& Roach, D. (2009). MIS versus computer science: An empirical study of the influences on the student's choice of major. Journal of Information Systems Education, 20(3), 357-368

9. Hogan, P.T., \& Li, L. (2010). The Perceptions of Business Students Regarding Management Information Systems (MIS) Programs, Journal of Technology Research [online]. Available www.aabri.com/manuscripts/09389.pdf

10. Saunders, G., \& Lockridge, T. (2011). Declining MIS enrollment: The death of the MIS degree? Contemporary Issues in Education Research (CIER), North America, 4,(1), 15-26 [online]. Available http://journals.cluteonline.com/index.php/CIER/article/view/978

11. Downey, J.P, McGaughey, R., \& Roach D., (2011). Attitudes and Influences toward Choosing a Business Major: The Case of Information Systems. Journal of Information Technology Education 10, 231-251

12. Frankel, D. S. (2008). Danger: MIS Schools in Decline, MDA Journal [online]. Available www.bptrends.com/publicationfiles/09-08-COL-MDA\%20Journal-\%20MIS\%20Schools-Frankel\%20v01-00final.pdf

13. Tabatabaei, M., \& Tehrani, M. (2010). Factors impacting enrollment in information systems programs. Issues in Information Systems, 17(1), 319-321

14. Walstrom, K. A., Schambach, T.P., Jones K.T. \& Crampton W.J. (2008). Why are Students Not Majoring in Information Systems? Journal of Information Systems Education, 19 (1), 43-54

15. ACIS (2011). Australasian Conference on Information Systems (ACIS) [online] Sydney, Australia30th November - $2^{\text {nd }}$ December, 2011; Available www.acis2011.org

16. Cohen, J.F. and Parsotam, P. (2010). Intentions to Pursue a Career in Information Systems and Technology: An Empirical Study of South African Students. Key Competencies in the Knowledge Society IFIP Advances in Information and Communication Technology, 324, 56-66

17. Cohen, J., \& Hanno, D. (1993). An analysis of underlying constructs affecting the choice of accounting as a major. Issues in Accounting Education, 8(2), 219-238

18. http://infonet.tscpa.net/docushare/dsweb/Get/Document-594/albrechtrept.pdf

19. Simons, K.A., Lowe D.R. \& Stout D. E. (2003). Comprehensive literature review: Factors influencing choice of accounting as a major. Proceedings of the 2003 Academy of Business Education Conference [online] www.abe.sju.edu/proc2003/simons.pdf

20. Tan, L.M. and Laswad, F. (2006). Students' beliefs, attitudes and intentions to major in accounting, Accounting Education, 15(2), 167-187

21. Beggs, J.M., Bantham J.H. \&Taylor S. (2008). Distinguishing the factors influencing college students' choice of major, College Student Journal, 42(2), 381- 394

22. Tillberg, H.K. \& Cohoon, J.M. (2005). Attracting women to the CS major. Frontiers 26(1), 126-140 


\section{Issues in Information Systems}

Volume 13, Issue 2, pp. 58-71, 2012

23. Zhang, W (2007). Why IS: understanding undergraduate students' intentions to choose a information systems major. Journal of Information Systems Education 18(4), 447-458

24. Li, L., \& Thomson, N., (2011). Why business students select MIS as their major- An empirical examination. Proceedings of the Southern Association for Information Systems Conference, Atlanta, GA, USA March $25^{\text {th }}$ $26^{\text {th }}, 109-112$

25. Klein, K. K. \& Myers, M. D. (1999). A Set of Principles for Conducting and evaluating Interpretive Field Studies in Information Systems. MIS Quarterly, 23(1), 67-94

26. Walsham, G. (1995). The Emergence of Interpretivism in IS Research, Information Systems Research, 6(4), 376-394.

27. Katz, M. L. \& Shapiro, C. (1985). Network Externalities, Competition, and Compatibility. American Economic Review 75, 424-440.

28. Straub, D. W. (1989). Validating instruments in MIS research. MIS Quarterly, 10(2), 147-169

29. Ferratt T.W., Hall S.R., Prasad J. \& Wynn D.W.Jr (2010). Choosing Management Information Systems as a Major: Understanding the smiFactors for MIS. Communication of the Association of Information System, 27 (16), 266-284 